\title{
La tinta y la bata blanca
}

\author{
Alain Massieu Paulin y Rocío Carolina García Rivera
}

\begin{abstract}
Resumen
Existe evidencia de que el ser humano se ha tatuado desde el 3300 a.C., desde entonces, los tatuajes han cambiado significativamente en sus propósitos y significados. En la actualidad, se ha producido un cambio en la cultura del tatuaje, alejándose de la idea que las personas tatuadas son sólo criminales o marineros. Cada vez es más frecuente observar profesionistas con tatuajes, sin embargo, aún existen prejuicios que afectan la vida de muchos de ellos, especialmente de los profesionales de la salud. Este artículo busca exponer cómo el auge del tatuaje ha traído nuevos retos a los médicos, ya sean infecciones en la piel, cuestiones éticas o personales, así como el de combatir el estereotipo que existe de ellos.
\end{abstract}

Palabras clave: tatuajes, tattoo, medicina, discriminación, salud.

\section{THE INK AND THE WHITE COAT}

\begin{abstract}
There is evidence that human beings have been tattooed since 3300 BC. Since then, tattoos have changed significantly in their purposes and meanings. Today, there has been a change in tattoo culture, moving away from the idea that tattooed people were limited to criminals or sailors. It is becoming increasingly common to observe professionals with tattoos. However, there are still prejudices that affect the lives of many of them, especially health professionals. This article seeks to expose how the rise of tattoos has brought new challenges to doctors, whether they are skin infections, ethical or personal issues, as well as to combat the stereotype that exists of them.
\end{abstract}

Keywords: tattoo, ink, medicine, discrimination, health.

Recepción: 27/09/2020. Aprobación: 17/02/2021. Dol: http://doi.org/10.22201/cuaieed.16076079e.2021.22.5.1 
Alain Massieu Paulin

massieu@gmail.com

orcid.org/0000-0002-3526-0094

Twitter: @alainmassieu Instagram: @alainmassieu

Médico Cirujano y Maestro en Ciencias Sociomédicas por parte de la Facultad de Medicina de la Universidad Nacional Autónoma de México (UnAm). Actualmente labora como profesor titular de las asignaturas de Integración Básico Clínica I y ॥ en la Facultad de Medicina de la unam y se encuentra cursando el Doctorado en Educación en Ciencias de la Salud. Cuando tenga dinero piensa hacerse un tatuaje nuevo.

\section{Carolina García}

Médica Cirujana y Maestra en Ciencias Sociomédicas por parte de la Facultad de Medicina de la unAm. Su pasión por la docencia la ha llevado a ser profesora titular de las asignaturas de Integración Básico Clínica y Microbiología y Parasitología en la Facultad de Medicina de la unAm y de la asignatura de Microbiología en la Escuela de Medicina Saint Luke. Ha sido adscrita a la Secretaría de Educación Médica de la Facultad de Medicina de la unAm y actualmente labora como directora ejecutiva de Innovación Educativa de la Universidad de la Salud. 


\section{Introducción}

Lejos han quedado los días en que se consideraban a las personas tatuadas como criminales o marineros; en que los tatuadores ejercían su oficio en la clandestinidad o que las personas ocultaban sus tatuajes por temor a ser juzgados o discriminados. Cada vez es más común observar personas utilizando ropa que permita mostrar los diseños que llevan en la piel, ya sea un noventero tribal en el brazo, un retrato de algún ser querido, un símbolo religioso o una "manga" completa inspirada en la cultura asiática. No es difícil comprender que muchos jóvenes se quieran "rayar" si varios de sus ídolos tienen el cuerpo cubierto de tinta - personalidades tan variadas como el futbolista Lionel Messi, el cantante pop Ed Sheeran o el difunto rapero Lil Peep pueden servir de ejemplo- y actualmente ya podemos mencionar a tatuadores que han alcanzado el estatus de superestrellas como Kat Von D, Ami James, Jon Boy o Nikko.

Un tatuaje es una pigmentación permanente de la piel causada por la introducción de sustancias exógenas; cuando sucede de forma accidental se llama tatuaje traumático, de lo contrario se pueden clasificar en: amateurs, profesionales, cosméticos o médicos. La razón por la que son permanentes involucra al sistema inmune y es francamente interesante. Para su realización, por lo general, se utilizan agujas montadas a una máquina de motor eléctrico (diseñada originalmente por Thomas Alba Edison en 1876) que oscila a una frecuencia de 50 a 3000 vibraciones por minuto. Estas agujas cubiertas de tinta traspasan la epidermis (la capa más superficial de la piel)y depositan los pigmentos en la siguiente capa, la dermis. Este proceso causa una lesión que activa al sistema inmune: miles de células, llamadas fagocitos, acuden al sitio lastimado y empiezan a "comerse" los pigmentos, aunque algunas de estas células siguen su camino por los vasos linfáticos", muchas se quedan llenas de tinta en la dermis. También otras células de la piel llamadas fibroblastos absorben los pigmentos y de igual forma se quedan "varadas" en este nivel (Aguirre, 2014; Lintz, 2013).

Video . La elaboración de un tatuaje (Stéphane Couchoud, 2014)

${ }^{1}$ Los vasos linfáticos son "canales" que recorren todo el cuerpo y que transportan "desechos" y células del sistema inmunitario.

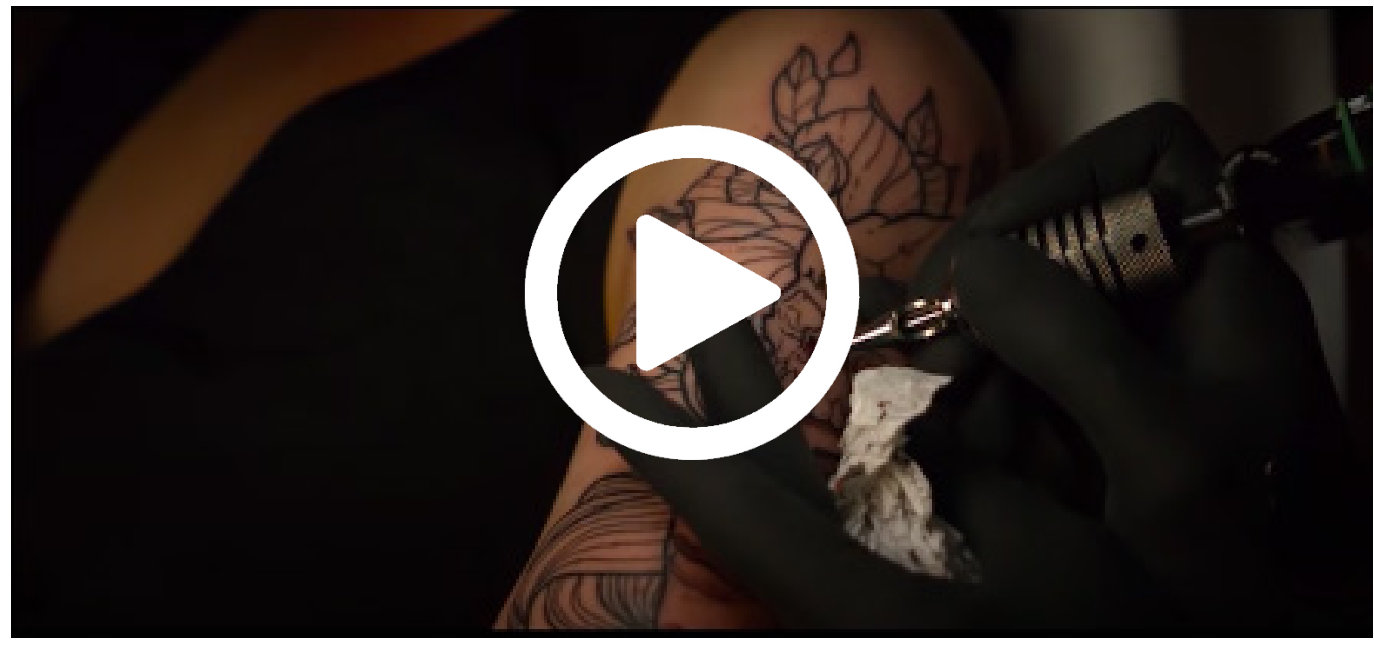


Independientemente de la fisiología del tatuaje o su diseño, el tatuaje es un medio que permite al sujeto expresarse sobre sí mismo, como testimonio de su evolución, su historia y por ello sus significados son profundamente personales (Sastre, 2011). Los médicos y profesionales de la salud no son ajenos a los cambios culturales y sociales, por lo que ahora enfrentan nuevos retos derivados del auge de la práctica: ya sean problemas de salud de sus pacientes, conflictos éticos o personales como la discriminación.

Imágenes 1 y 2. Tatuajes de los autores de este escrito.
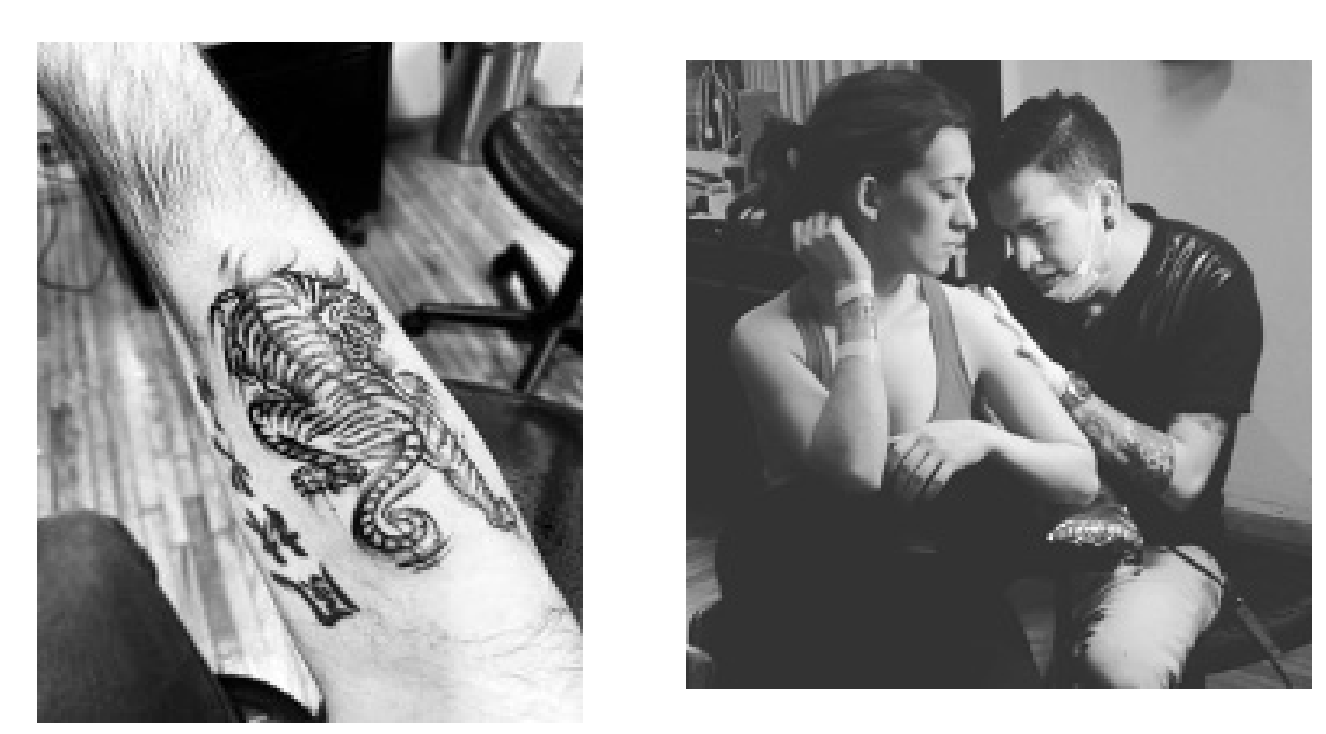

\section{La tinta a través de la historia}

La humanidad se ha adornado la piel con tinta desde hace miles de años. Estos diseños han servido a manera de amuletos, símbolos de estatus social o religiosos, formas de castigo o simplemente como un adorno. La primera evidencia de un tatuaje se encontró en Ötzi, el hombre de hielo cuyos restos momificados fueron localizados en 1991 por los exploradores Helmut y Erika Simon en la montaña Finialspitze, ubicada en la frontera austro-italiana. Al realizarle estudios, se determinó que se trataba de un cuerpo del 3300 a.C. (Pesapane, Nazzaro, Gianotti y Coggi, 2014; Mayans, 2018).

En el antiguo Egipto (2000 a.C.), las mujeres se tatuaban a manera de amuletos para proteger el embarazo y la gestación, como lo hemos podido saber a través de sus cuerpos momificados. En los tiempos clásicos, entre los griegos y los romanos, los tatuajes eran usados para mostrar la pertenencia a alguna secta religiosa o, en el caso de los esclavos, a una persona. Igualmente existe evidencia de la ornamentación del cuerpo en las civilizaciones precolombinas del Perú y Chile, en donde sus habitantes se tatuaban las extremidades, el torso e inclusive la cara. Los polinesios desarrollaron complejas formas geométricas que llamaban tattau - palabra que describe la acción de golpear algo y de ahí la palabra en inglés tattoo (Anderson, 2014; Lineberry, 2007). 
Imagen 3. Tatuaje facial tradicional maorí conocido como moko. Foto: Geof Wilson.

Imagen 4. Vladimir Franz. Fuente: Wikimedia Commons.

${ }^{2}$ Algunos ejemplos son: tradicional americano caracterizado por sus líneas gruesas y motivos icónicos como anclas, rosas o calaveras; el reciente estilo realista que suele usarse en retratos; tatuajes geométricos o estilo acuarela que están de moda entre los millennials; los tribales, uno de los estilos más antiguos o el tradicional japonés que originalmente se creó durante el periodo Edo (1603-1866) inspirado en el arte ukiyo-e.

${ }^{3}$ Hipócrates fue un médico de la Antigua Grecia y es por muchos considerado el padre de la medicina, al separar esta disciplina de la filosofía y establecerla como una profesión.

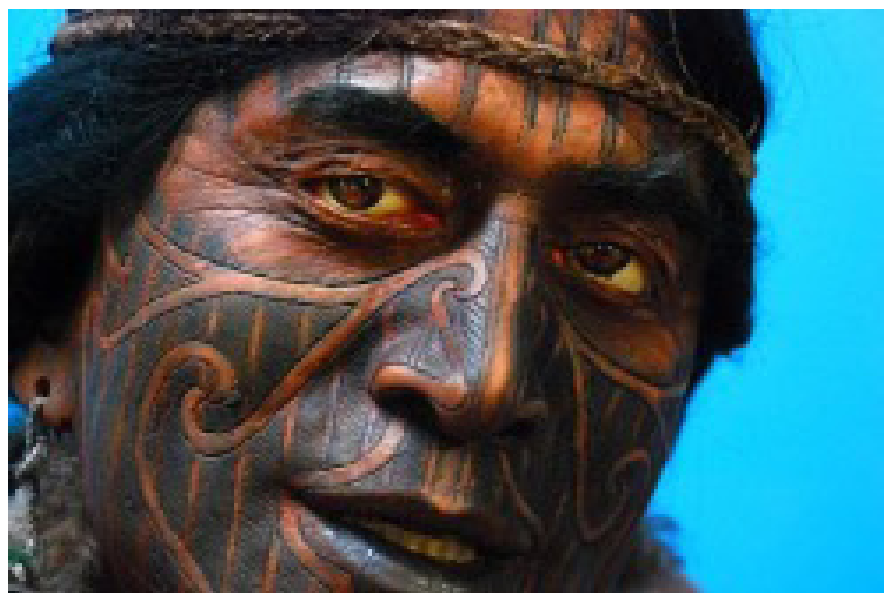

Hoy en día podemos hablar de distintas escuelas del tatuaje ${ }^{2} y$, de acuerdo con el Consejo Nacional para Prevenir la Discriminación (CONAPRED), en México una de cada 10 personas tiene uno; es decir, alrededor de 12 millones de personas. En los Estados Unidos, aproximadamente $40 \%$ de la población, entre 26 y 40 años, tiene al menos un tatuaje. También se calcula que esta industria (junto con la de las perforaciones y la de remoción láser) vale tres mil millones de dólares (Meza, 2019; Jiménez, 2018; Hsu et al., 2016).

\section{La tinta debajo de la bata blanca}

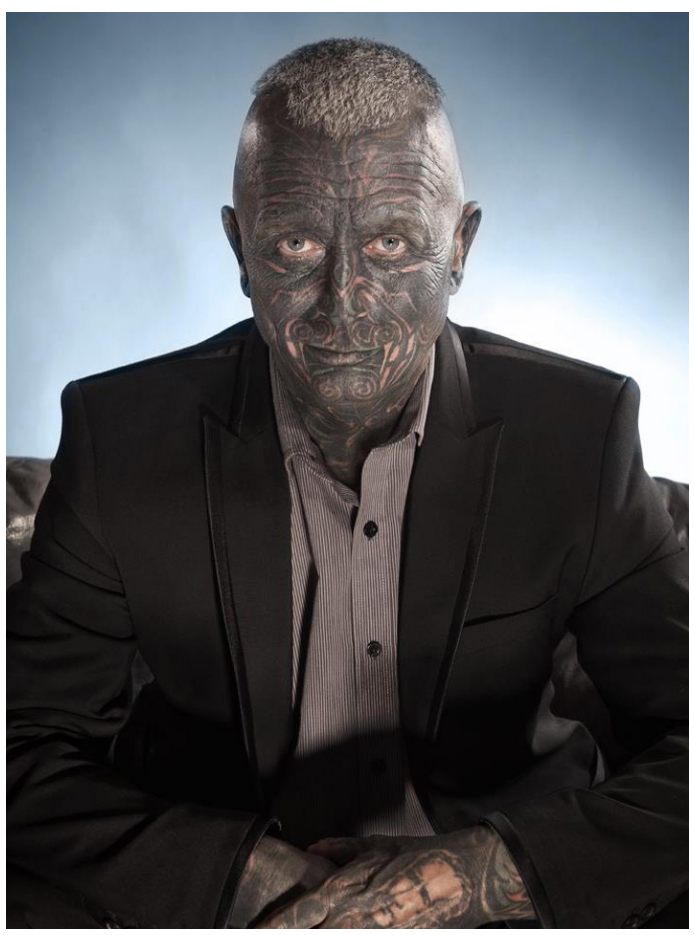

Al imaginarse una persona tatuada, es fácil caer en prejuicios o estereotipos, quizás se piensa en motociclistas que manejan una Harley Davidson o en roqueros sobre el escenario, pero ¿un primer ministro, un profesor o un médico? Justin Trudeau, primer ministro de Canadá, tiene tatuado el brazo izquierdo y Vladimir Franz, un abogado, profesor universitario, músico y escritor, obtuvo una relativa fama al ser candidato presidencial en la República Checa en 2013..., por tener 90\% del cuerpo tatuado (ver imagen 4).

Cuando pensamos en un profesional de la salud, la imagen que tenemos es la de una persona de "buena" apariencia, con vestimenta formal y una bata blanca, pero, ¿de dónde proviene este estereotipo? Desde tiempos de Hipócrates ${ }^{3}$, a los médicos se les impuso tener una imagen que los identificara como tales. En un texto denominado Sobre el médico, Hipócrates describió: 
La prestancia del médico reside en que tenga buen color y sea robusto en su apariencia [...] que presente un aspecto aseado, con un atuendo respetable y perfumado con ungüentos de buen aroma. [...] Que haga su examen con cierto aire de superioridad (Hoyos, 1998).

Por lo tanto, construyendo la imagen de lo que un médico debe ser, desde la época Hipocrática, es difícil imaginar un médico o profesional de salud con los brazos tatuados, cabello morado o con un piercing en el labio.

Dentro del gremio médico, la doctora Sarah Gray ha cobrado notoriedad por ser considerada "la médica más tatuada del mundo". La aspirante a cirujana ortopedista se describe como "la doctora más colorida del pabellón" y está determinada en acabar con los prejuicios. Cree que, "si uno está seguro de sí mismo y es competente en su trabajo, las apariencias no deberían de importar". De igual forma, asegura que su apariencia ayuda en la relación médico-paciente con los más jóvenes (Lavender, 2019, ver imagen 5).

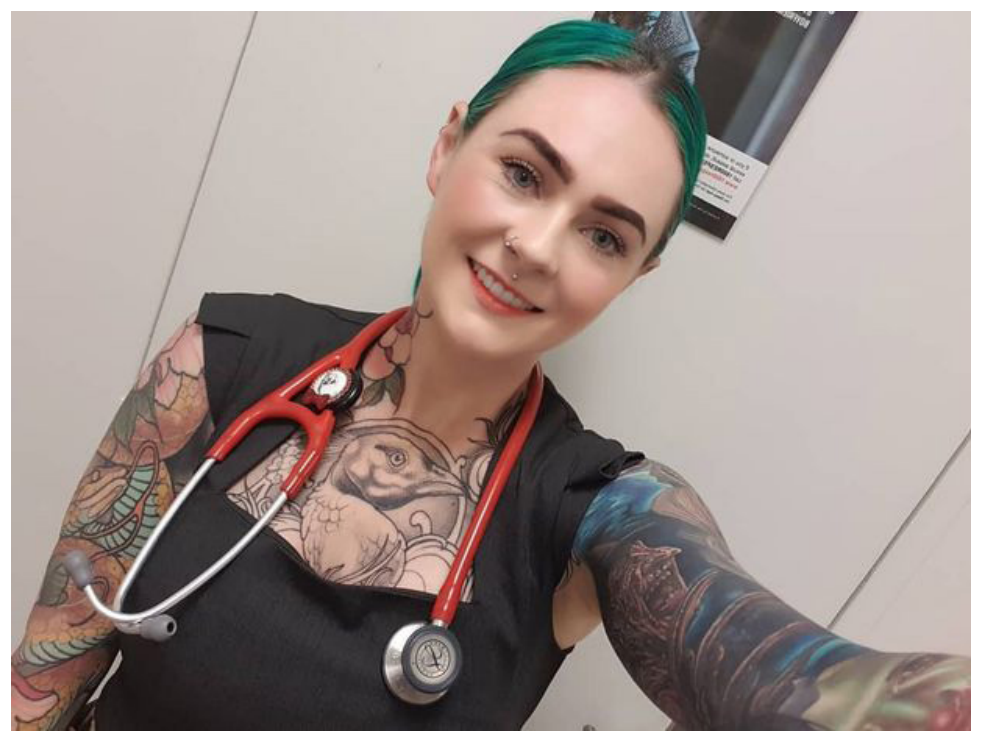

Ampliamente son conocidas las frases "no se debe juzgar un libro por su portada", "el hábito no hace al monje"; sin embargo, la evidencia muestra que un profesional de la salud que no se apega al estereotipo de apariencia, es percibido por los pacientes y colegas como menos competente $\quad y$ confiable (Motluk, 2018). Westerfield et al. (2012) evidenciaron que los pacientes consideraron al personal médico, que muestra tatuajes, como menos confiable, cercano, profesional, atento o cooperador (en especial si son mujeres). Callaghan y McConville (2018) estudiaron la impresión que tenían los estudiantes y personal de medicina de la Universidad de Dundee respecto a los médicos tatuados: todos los participantes aseguraron que la percepción hacia las personas tatuadas ha cambiado mucho en tiempos recientes, pero también cuestionaron la forma en que un tatuaje visible podría afectar el profesionalismo, creando conflictos entre la libre expresión, la identidad personal y la profesional.

A pesar de que pareciera que los estigmas hacia los profesionales de la salud "rayados" siguen predominando, esto podría cambiar si cada vez más y más profesionistas con tinta en la piel se hacen presentes. Dickinson et al. (2014) señalan que, conforme se vuelve más habitual la costumbre del tatuaje, grupos de personas más diversas se acercarán a esta práctica; como resultado, tendrán 
contacto con familiares y amigos tatuados, lo que cambiará su percepción y concientizarán que sus ideas están basadas en estereotipos.

\section{La tinta y la salud}

El auge de la cultura del arte corporal ha traído varias implicaciones y problemas de salud que vale la pena repasar. Una complicación médica asociada al tatuaje puede definirse como experiencias u observaciones anómalas causadas por este mismo. La principal es la alergia a la tinta, lo que puede llevar a distintas dermatitis; esto sucede cuando el cuerpo reacciona a los pigmentos que suelen ser creados a partir de metales. Otra complicación causada por las microheridas infringidas por la aguja son las infecciones (principalmente cuando no se trabajó con equipo esterilizado). Entre los agentes infecciosos más frecuentes se encuentran bacterias, pero también los virus de la hepatitis B y C. Es importante mencionar que no existe evidencia que confirme que la tinta negra es causa de melanomas (cáncer), pero sí puede ocultar nevos o lunares con potencial maligno (Guzmán 2020; Serup, Hutton Carlsen y Sepehri, 2015).

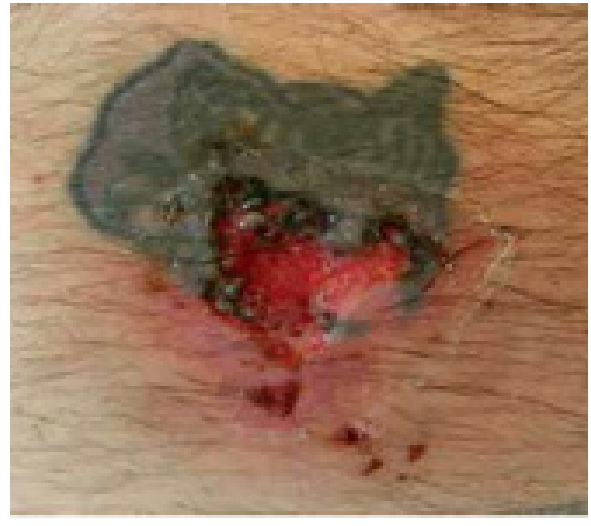

La remoción de tatuajes por láser es otra industria que ha visto un crecimiento en años recientes. Para esta tarea llamada fototermólisis se utilizan láseres de diferentes longitudes de onda que fragmentan pigmentos de colores determinados para que así el sistema inmune pueda eliminarlos. Es importante señalar que algunos tatuajes (principalmente los que son recientes y coloridos) jamás llegarán a desaparecer completamente y el tratamiento láser puede acompañarse de complicaciones como cambios en la textura y coloración de la piel, dejando cicatrizaciones poco estéticas (Hsu et al., 2016; Kuperman, Levine y Ashinoff, 2001).

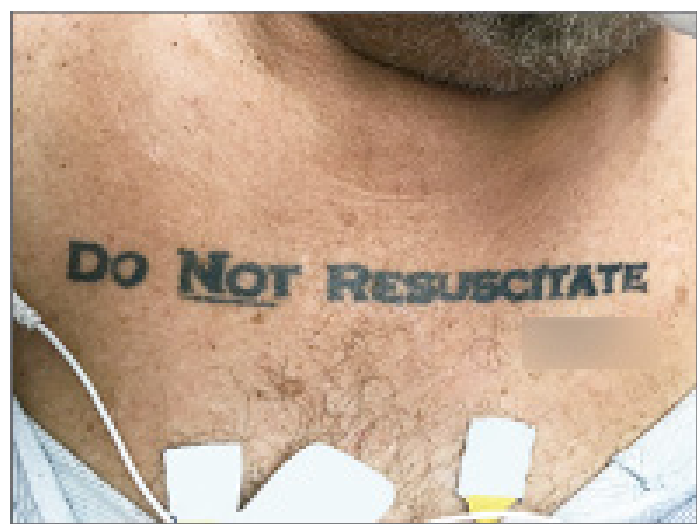

Otro reto que ha traído los tatuajes a los profesionales de la salud es el de pacientes que arriban a los servicios de urgencias en estado crítico y que cuentan con tatuajes de "no reanimación"4 (ver imagen 7). Este deseo plasmado en la piel puede traer mucha confusión a los equipos de salud al cuestionar su legalidad o considerar que el tatuaje no representa el deseo actual del paciente - esto último fundado en la idea de que muchos tatuajes son motivo de arrepentimiento (Holt, Sarmento, Kett y Goodman, 2017)—. 


\section{Conclusiones}

Las nuevas generaciones han crecido viendo a sus ídolos con el cuerpo cubierto de tinta; también cada vez conviven más y más con familiares o amigos cercanos que tienen alguna parte del cuerpo tatuada y han roto con varios estereotipos. Estas nuevas generaciones, que han popularizado el arte corporal y han hecho crecer dicha industria, son las que actualmente están en los salones de clases de distintas Facultades de Medicina o que en algún momento necesitarán de servicios médicos. Probablemente estos jóvenes, como parte de su libre expresión y de su identidad personal, se deseen y vayan a tatuar, exigiendo nuevas dinámicas en la relación médico-paciente.

\section{Referencias}

* Aguirre, C. (2014). What makes tattoos permanent? https://ed.ted.com/lessons/ what-makes-tattoos-permanent-claudia-aguirre

- Callaghan, B. y McConville, K. (2018, 2 de marzo). The tattooed doctor: An exploration of the perceptions of medical students and medical school staff. MedEdPublish, 7(1). https://doi.org/10.15694/mep.2018.0000049.1

* Dickson, L., Dukes, R., Smith, H. y Strapko, N. (2014, 12 de marzo). Stigma of ink: Tattoo attitudes among college students. The Social Science Journal, 51(2), 265-276. https://doi.org/10.1016/j.soscij.2014.02.005

* Guzmán, F. (2020). Los males más comunes por tatuarse. Gaceta unam. https:// www.gaceta.unam.mx/especial-tatuajes-los-males/

* Holt, G., Sarmento, B., Kett, D. y Goodman, K. (2017, 30 de noviembre). An Unconscious Patient with a DNR Tattoo. New England Journal Of Medicine, 377(22), 2192-2193. https://doi.org/10.1056/NEJMc1713344

* Hoyos Zuluaga, J. E. (1998, junio). Hipócrates y la medicina mono-discursiva. Affectio Societatis. https://revistas.udea.edu.co/index.php/affectiosocietatis/ article/view/5456

- Hsu, V., Aldahan, A., Mlacker, S., Shah, V. y Nouri, K. (2016, septiembre). Picosecond laser for tattoo removal: a systematic review. Lasers In Medical Science, 31(8), 17331737. https://doi.org/10.1007/s10103-016-2001-0

* Jiménez, N. (2018, 15 de octubre). En auge, el mercado del tatuaje. La Jornada. https://www.jornada.com.mx/2018/10/15/sociedad/037n3soc

* Kuperman, M., Levine, V. y Ashinoff, R. (2001). Laser removal of tattoos. American Journal of Clinical Dermatology, 2(2), 21-25. https://doi.org/10.2165/00128071200102010-00004

- Lavender, J. (2019, 26 de septiembre). 'World's most tattooed doc' wants to challenge stereotypes in medical profession. Mirror. https://cutt.ly/PQ6Hihv 
* Lineberry, C. (2007, 1 de enero). Tattoos The Ancient and Mysterious History. Smithsonian Magazine. https://cutt.ly/3Q6HkAG

* Lintz, C. (2013, 13 de junio). FYl: What Makes Tattoos Permanent? Popular Science. https://www.popsci.com/science/article/2013-06/fyi-what-makes-tattoospermanent/

* Mayans, C. (2018, 18 de septiembre). Ötzi, el hombre de hielo rescatado en las cumbres alpinas. Historia. National Geographic. https://cutt.ly/pQ6Hb2s

* Meza, N. (2019, 21 de febrero). Con olor a tinta. Reporte Índigo. https://cutt. ly/8Q6HU8R

* Motluk, A. (2018, 27 de agosto). Is it unprofessional for doctors to have tattoos or facial piercings? CMAJ, 190(34), E1026-E1027. https://doi.org/10.1503/cmaj.1095641

* Pesapane, F., Nazzaro, G., Gianotti, R. y Coggi, A. (2014, febrero). A Short History of Tattoo. JAMA Dermatology, 150(2), 145. https://doi.org/10.1001/ jamadermatol.2013.8860

* Sastre C, A. (2011, enero-junio). Cuerpos que narran: la práctica del tatuaje y el proceso de subjetivación. Diversitas: Perspectivas en Psicología, 7(1), 179-191. https://www.redalyc.org/articulo.oa?id=67922583013

* Serup, J., Hutton Carlsen, K. y Sepehri, M. (2015). Tattoo Complaints and Complications: Diagnosis and Clinical Spectrum. Tattooed Skin And Health, 48, 4860. https://doi.org/10.1159/000369645

- Stéphane Couchoud. (2014, 24 de septiembre). EPIC Tattoo in Ultra Slow Motion [video]. YouTube. https://youtu.be/LLhsJvB8HGM

* Ted-Ed. (2014, 18 de septiembre). La historia de los tatuajes - Addison Anderson [video]. YouTube. https://www.youtube.com/watch?v=MYn15yDBvxM

* Westerfield, H., Stafford, A., Speroni, K., y Daniel, M. (2012). Patients' Perceptions of Patient Care Providers With Tattoos and/or Body Piercings. JonA: The Journal of Nursing Administration, 42(3), 160-164. https://doi.org/10.1097/ NNA.0b013e31824809d6

\section{Cómo CITAR ESTE ARTículo}

* Massieu Paulin, Alain y García Rivera, Rocío Carolina. (2021, septiembre-octubre). La tinta y la bata blanca. Revista Digital Universitaria (RDU), 22(5). http://doi. org/10.22201/cuaieed.16076079e.2021.22.5.1 